Fall 12-13-2019

\title{
Occupational Therapy's Role in Maternal Mental Health within Transition from NICU to Home
}

\author{
Victoria Briltz \\ University of St. Augustine for Health Sciences
}

DOI: https://doi.org/10.46409/sr.FLDE1422

Follow this and additional works at: https://soar.usa.edu/capstones

Part of the Mental and Social Health Commons, and the Occupational Therapy Commons

\section{Recommended Citation \\ Briltz, V. (2019). Occupational Therapy's Role in Maternal Mental Health within Transition from NICU to Home. [Doctoral project, University of St Augustine for Health Sciences]. SOAR @ USA: Student Capstone Projects Collection. https://doi.org/10.46409/sr.FLDE1422}

This Capstone is brought to you for free and open access by the Student Research at SOAR @ USA. It has been accepted for inclusion in Student Capstone Projects by an authorized administrator of SOAR @ USA. For more information, please contact soar@usa.edu, erobinson@usa.edu. 
OCCUPATIONAL THERAPY'S ROLE IN MATERNAL MENTAL HEALTH WITHIN

TRANSITION FROM NICU TO HOME

by

Victoria, J, Briltz

A Capstone Project Proposal Presented in Partial Fulfillment

of the Requirements for the Degree

DOCTOR OF OCCUPATIONAL THERAPY

University of Saint Augustine for Health Sciences

December, 2019 
OCCUPATIONAL THERAPY'S ROLE IN MATERNAL MENTAL HEALTH WITHIN

TRANSITION FROM NICU TO HOME

by

Victoria, J, Briltz

has been approved

December 2019

APPROVED:

Susan MacDermott, OTD, OTR/L, Doctoral Coordinator

Becki Cohill, OTD, OTR/L, Doctoral Coordinator

Erin Schwier, EdD, OTD, OTR/L, Program Director

ACCEPTED AND SIGNED:

Susan MacDermott, Digitally signed by Susan

$\begin{array}{lll}\text { OTD, OTR/L } & \text { MacDermott, OTD, OTR/L } \\ \text { Date: 2019.12.19 10:23:38 -08'00' }\end{array}$

Susan MacDermott, OTD, OTR/L, Doctoral Coordinator

Becki Cohill OTD OTR/L

Becki Cohill, OTD, OTR/L, Doctoral Coordinator

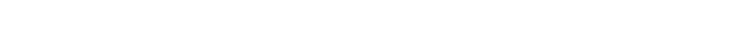

eschwier@usa.edu

Erin Schwier, EdD, OTD, OTR/L, Program Director 


\section{Table of Contents}

CHAPTER I. Introduction

Background

Statement of the Problem

Purpose Statement

Rationale for the Proposed Project

Significance of the Proposed Project

Preliminary Project Objectives

Assumptions

Limitations/Delimitations

CHAPTER II. Literature Review

Role of OT in Maternal Mental Health

Psychological Impact on the Maternal-Infant Relationship

Difficulty Transitioning Home from the NICU

CHAPTER III. Project Description

Methods

Participants

Materials and Design

Procedures and Timeline

Actual Procedures and Timeline

Data Analysis

Results 
$\begin{array}{ll}\text { CHAPTER V. Discussion and Conclusion } & 28\end{array}$

$\begin{array}{ll}\text { Discussion } & 28\end{array}$

$\begin{array}{ll}\text { Limitations } & 30\end{array}$

Implications for Occupational Therapy $\quad 31$

$\begin{array}{ll}\text { Conclusion } & 33\end{array}$

$\begin{array}{ll}\text { References } & 33\end{array}$

$\begin{array}{ll}\text { Appendix A } & 39\end{array}$

$\begin{array}{ll}\text { Appendix B } & 43\end{array}$

$\begin{array}{ll}\text { Appendix C } & 45\end{array}$ 


\section{Chapter I: Introduction}

\section{Background}

Occupational therapy $(\mathrm{OT})$ is a holistic profession that incorporates purposeful and meaningful occupations in order to promote performance in the daily activities of life.

Occupational therapy in maternal mental health provides services to support women who have a pre-existing perinatal mood disorder or high-risk infant (Slootjes, McKinstry, \& Kenny, 2016). Occupational therapists in European countries provide services to address the impact on occupational performance of symptoms experienced during pregnancy and post-partum (Mater Health and Wellness, 2012). Occupational therapists' role fit within care models by working on the same team with fertility specialists, nurses, midwives, and doulas. Due to limited collaboration, advocacy and evidence- based practice to support OT intervention within the field, the justification for OT in maternal mental health and greater clarification of OT's role needs to be further addressed (Slootjes, McKinstry, \& Kenny, 2016).

Maternal mental health describes women's mental health during pregnancy, childbirth, and the postpartum period (Podvey, 2018). Having a high-risk infant means there is a greater chance of complications because of conditions that occur during fetal development, pregnancy conditions of the mother, or problems that may occur during labor and birth (Stanford Children's Health, 2019). A traumatic childbirth raises concerns for the mother including loss of control, fear of losing the baby, threat to the mother's health, and threat to the baby's health (PizurBarkenow \& Erickson, 2011). The distress post birth and the stress of caregiving for a medically compromised infant may place mothers at greater risk for health consequences as opposed to mothers with healthy infants (Pizur-Barnekow, 2010). Poor maternal mental health may influence the child's developmental outcomes in conjunction with being a high- risk infant 
MATERNAL MENTAL HEALTH WITHIN TRANSITION

(Pizur-Barnekow, 2010). Impact is noted on the infant's future development and higher risk for chronic health conditions (Pizur-Barnekow, 2010).

The transition to motherhood is often anticipated with optimism. Therefore, postnatal experiences that do not match prenatal expectations can lead to the development of postnatal depression (Lazarus \& Rossouw, 2015). Maternal expectations are immediate recovery following childbirth. Society marks pregnancy as the most precious time in a mother's life (Podvey, 2018). Mothers blame themselves for their baby being admitted into the NICU and develop anxiety from consistent external exposure of "the perfect perinatal experience" via social media platforms (Podvey, 2018). Mothers who experienced difficulty conceiving and used fertility treatments face challenges normalizing to the birth experience (Podvey, 2018).

Up to $20 \%$ of pregnant or postpartum women experience perinatal mood disorders, including postpartum depression (PPD), perinatal post-traumatic stress disorder (PTSD) and postpartum anxiety, which negatively affect daily function during pregnancy and the post-birth year (Vismara, 2017). Perinatal post-traumatic stress disorder is a mood disorder that can occur around the childbirth period and is often undiagnosed (Pizur-Barkenow \& Erickson, 2011). Signs include fear, loss of control, and a sense of helplessness (Pizur-Barkenow \& Erickson, 2011). Symptoms of PTSD following a traumatic birth may not be apparent for months or years. They include avoidance, hyperarousal, and re-experience (Pizur-Barkenow \& Erickson, 2011). Postnatal stress post birth of a medically complex infant is consistent with PTSD symptoms (Pizur-Barnekow, 2010). In a study conducted by Pizur-Barnekow and Erickson (2010), 9 of 10 mothers reported PTSD symptoms following birth of a high- risk infant (p.646).

When babies experience a neonatal intensive care unit (NICU) stay, the medical team supports both mother and baby. A NICU is equipped and staffed with experts to provide 
MATERNAL MENTAL HEALTH WITHIN TRANSITION

intensive care to medically compromised or premature newborn babies (Dusing, Van Drew \& Brown, 2012). Hospitals have resources to provide mothers with comfort, continued updates on the baby, and assurance of a safe environment while the baby is hospitalized (Dusing, Van Drew \& Brown, 2012). The NICU environment can elicit stress for parents. Parents of sick infants in NICUs experience more stressors than parents who have a healthy infant (Heidari et al., 2017). They report the feeling of hopelessness provokes stress and the effort to maintain emotional selfcontrol is exhausting (Heidari et al., 2017). Sources of stress for parents include risk for parentinfant bonding detachment, the vulnerable medical state of the infant, and feeling unskilled to raise an infant with future developmental needs (Heidari, Hasanpour \& Fooladi, 2017). Parents can overcome their emotional distress through seeking information, finding hope, attachment to the infant, communicating with the medical team, remaining calm, and focusing on spirituality (Heidari et al., 2017).

\section{Statement of the Problem}

Mothers may feel unprepared for the discharge home when their babies are ready to leave the NICU (Boykova, 2016). When resources are not available, mothers are forced to learn how to care for their premature infants through trial and error (Boykova, 2016). Mothers often struggle with parenting and intensive caregiving duties such as tube feeding, home oxygen requirements, and monitoring vital signs (Boykova, 2016). Parents describe their post-discharge parenting as challenging (Boykova, 2016). The demands of an infant recently discharged from the NICU places high physical stresses on the parents, causing sleep deprivation, fatigue, and exhaustion (Boykova, 2016). Having an infant who was hospitalized in the NICU also alters their perception of their role as a parent. Parents of infants who in the NICU demonstrated lowered selfconfidence and produced feelings of 'not being a parent' because medical staff were the primary 


\section{MATERNAL MENTAL HEALTH WITHIN TRANSITION}

caregivers (Boykova, 2016). Role alteration and desire to protect their premature infant from possible health risks often leads to social isolation (Boykova, 2016). The result of social isolation leads to a misunderstanding of the infant's conditions and needs from parents' close social networks due to societal separation from the outside world (Boykova, 2016).

Occupational therapists address occupational performance through skilled interventions for women during the perinatal period; however, there is a lack of evidence guiding occupational therapy for providing services for maternal wellness (Slootjes, 2016). Potential roles of OT practice in this area could include professional support upon transition home, as well as providing education and individualized care for families when discharging them home. Boykova (2016), determined that parents' emotional and psychological wellbeing was influenced by professional support upon transitioning home. Parents also identified they wanted health care professionals who were more educated in caring for preterm infants, and individualized care to help reassure that their parenting and caregiving skills are supported post-discharge (Boykova, 2016). The need to support postpartum depression screening has been supported by the literature (Cherry et al., 2016). There is potential for future research in maternal mental health; particularly regarding perinatal PTSD as little is known about its effects on the occupation of mothering (Pizur-Barkenow \& Erickson, 2011).

\section{Purpose Statement}

The purpose of this capstone project is to identify OT's role in maternal mental health following the transition home from a NICU setting. This capstone project will focus on mothers' roles, routines, and environment during the transition from the NICU to home. The primary objective will be to address the mental health stressors that follow mothers into their natural environment. 
MATERNAL MENTAL HEALTH WITHIN TRANSITION

\section{Rationale for the Proposed Project}

Pregnant and postpartum women undergo physiological changes affecting their mental, emotional, and physical health that go beyond the parenting experiences of fathers, adoptive parents, and non-birth partners (Haas et al., 2005). Post-birth obstetrical follow-up typically occurs six weeks postpartum but perinatal mood disorders can be identified within the first month postpartum (Kurtz, Levine, \& Safyer, 2017: Tully, Stuebe, \& Verbiest, 2017).

The Model of Human Occupation (MOHO) can be used by occupational therapists working in the field of inpatient pediatrics or early intervention (EI) for mothers and families who experienced a NICU stay in conjunction with having a premature infant (Kielhofner, 1998). MOHO is an occupational therapy model which addresses motivation and, occupational patterns such as, habits, roles, and routines within an individual engaging in an occupation (Kielhofner, 1998). MOHO is useful in understanding the occupational impact of perinatal mood disorders (Pizur-Barkenow \& Erickson, 2011). Using MOHO will help identify what is important to a mother, areas of concern related to roles and routines, and how to solidify a client-centered approach to improve client outcomes. Two elements within MOHO that can be altered if experiencing perinatal mood disorder are habits and roles. A mother experiencing PTSD symptoms may have difficulty forming parenting occupations which could lead to altered attitudes and/or perceptions about her role as a mother (Pizur-Barkenow \& Erickson, 2011). Using the theoretical framework from MOHO could help provide ways for the mother to establish a co-occupational bond.

\section{Significance of the Proposed Project}

The significance of this capstone project is that it can contribute to the awareness of maternal mental health, and maternal needs during the transition home from the NICU with a 
MATERNAL MENTAL HEALTH WITHIN TRANSITION

premature or medically fragile infant. It can contribute to programming designed to enhance maternal transition and promote OT's role in maternal mental health. The proposed project will help share information, ideas, and resources for occupational therapists providing services in maternal wellness.

\section{Preliminary Project Objectives}

- Build rapport with families through observations in an EI program serving infants and young children.

- Complete a needs assessment to assess the occupational needs of mothers during the transition from the NICU through observation, interviews with families and therapists, and semi-structured assessment.

- Formulate and deliver a questionnaire for mothers to determine how their occupations are impacted.

- Conduct interviews to compare the differences in roles, routines, and environment post transition home from the NICU.

- Develop and propose a program that addresses occupational performance challenges of early motherhood, including the complexities of establishing healthy roles, routines, and coping strategies from assessment results to promote positive maternal mental health.

- Propose the developed program to the families, Stars Therapy Services, and to the OT profession at large.

\section{Assumptions}

This capstone project is based on a few core assumptions. One assumption is that a mother's roles and routines will be compromised when returning home from the NICU. The early intervention team plan of care is solely addressing the baby's developmental needs and 
MATERNAL MENTAL HEALTH WITHIN TRANSITION

lacks consideration towards the mother's roles, routines and environment. Another assumption is that, a professional on the intervention team is not already providing similar support when addressing routines and roles as outlined above. The final assumption is, that mothers will neglect the occupations of self-care, leisure and social participation.

\section{Limitations and Delimitations}

Limitations could include the refusal of services: mothers may not have the time to sit down for an interview or may not be comfortable addressing the mental health aspect of having a newborn who is high risk. Options will be given to break the interview into parts and conduct interviews at times that are convenient for the mother. There are a few delimitations that correspond with the project. A qualitative approach was chosen because descriptive studies that use a phenomenological framework including comprehensive summarizations of specific events experienced by individuals. The outcome of the descriptive summary is organized in a way that findings will be presented in a direct manner. Early intervention providers should maintain flexibility and consideration of family schedule due to complex needs of premature infant. The roles and routines of being a mother may change her typical daily routine and schedule, which requires being flexible and adheres to the goal of gaining familiarity. Early intervention providers should maintain flexibility and consideration of family schedule due to complex needs of premature infant.

\section{Chapter II: Literature Review}

The purpose of this proposed project is supported through a literature review. One of the prevalent themes was the role of OT in maternal mental health as an emerging practice area. Gaps shown in the literature suggests that OT serves a purpose on the healthcare team to address these shortcomings. Another theme was that the transition from the NICU to home is currently 
MATERNAL MENTAL HEALTH WITHIN TRANSITION

an area of focus solely for the child however, the evidence determines there is a need to address the mother as well.

\section{Role of OT in Maternal Mental Health}

Based upon current literature, OT plays a role in the promotion of mental health through skilled interventions to help prevent the risk of experiencing substance, behavioral, and psychiatric disorders (American Occupational Therapy Association, 2017). The fourth trimester is twelve weeks postpartum with interrelated health domains under which an occupational therapist's scope of the practice lies. The domains are mood and emotional wellbeing, infant care and feeding, sexuality, contraception and birth spacing, sleep and fatigue, physical recovery, medication, substances and exposures lability (Tully, Stuebe, Verbiest, 2017).

Research describes the maternal role transition and why new mothers would benefit from OT. Some examples demonstrating the role of OT is as follows (Slootjes, McKinstry \& Kenny 2016):

- Addressing postpartum issues and impact of pregnancy symptoms on occupational performance

- Addressing psychosocial, physical, and emotional needs in the community, inpatient and outpatient settings

- Addressing co-occupations during perinatal care by promoting mother-infant bonding

- Promoting positive self-efficacy, self-confidence, and self-acceptance

- Facilitating successful transitions to reduce maternal role strain

- Improving muscle strength, postural alignment, body image, and regulation of blood pressure

- Proper ergonomics in caring for children to reduce musculoskeletal symptoms 
MATERNAL MENTAL HEALTH WITHIN TRANSITION

- Improving emotional wellbeing through a holistic health outcome through client-centered occupational participation

- Stress/ anxiety management, relaxation techniques

- Returning home to resume family-centered routines

- Maintaining a household while simultaneously caring for children, pregnant, and employed

- Group treatment

- Community resources

- Mobilizing social support, developing realistic expectations

Recommendations such as coordinated care throughout the perinatal period, resources to support maternal mental health and healing, wellness, and role adaptation need to be addressed as these issues are neglected (Verbiest, Bonzon \& Handler, 2016). Further research in OT's role in maternal group treatment for PPD, guiding interventions through OT frameworks, and developing comfortability to address maternal mental health (Goodman \& Santangelo, 2011: Slootjies et all., 2016: Tully et al., 2017).

\section{Psychological Impact on the Maternal-Infant Relationship}

Insecure attachments of both mother and child have been identified as a risk factor for child development and early regulation disorders (Bettz et al., 2015). Parenting interventions include but not limited to: handling and caring procedures, clothing and bathing, the general condition of the infant, ordinary care and guidance, health and developmental checkup and car seat instructional programs (Evans et al., 2014). These interventions are effective in improving the maternal-infant bond (Evans et al., 2014). There are currently models available to guide 
MATERNAL MENTAL HEALTH WITHIN TRANSITION

parenting interventions from birth on, for example, Mother Infant Transactional Program (MITP), Victorian Infant Brain Studies (VIBeS), and the Plus program to help provide mental health support for parents.

Mothers mental health symptoms appear to have a neurodevelopmental origin, assessing early on postpartum might aid in detecting early difficulties (Johnson \& Marlow, 2014). The relationship between maternal mental health and preterm social-emotional development in the preterm infant lays the foundation for potential cognitive deficits (Johnson \& Marlow, 2014). To improve maternal-infant bonding, mothers adopt supported attention (joint attention) play to support infants' cognitive, neurological and social-emotional development. Shared engagement in activities and communication in the home has a benefit to strengthen the parent-child relationship (Treyvaud, 2012). Supporting parents in the home is important given the influence of the parent-infant relationship on developmental outcomes and higher rates of mental health problems in mothers after a preterm birth (Spittle \& Treyvaud, 2016). A survey was conducted to over 176 mothers exploring experience and expectations of motherhood, and level of support and sense of self as predictors of anxiety, self-esteem, depression, and stress. Birth expectations surpassing experience increased levels of anxiety, depression and stress while consequently, selfesteem was lowered (Lazarus \& Rossouw, 2015). Karin, Britt-Marie \& Jens (2003), found mothers demonstrated fear of being responsible for the preterm infant, felt insecure, expressed the need to interact and socialize with mothers who had a similar experience, and feared something bad would happen to the baby.

\section{Difficulty Transitioning Home from the NICU}

Mothers of infants born less than 37 weeks gestational age participated in a transitional home program between 2012-2015; the program focused on perceptions regarding discharge 
MATERNAL MENTAL HEALTH WITHIN TRANSITION

readiness, staff support, medical stability of the infant, maternal well-being, and maternal comfort (Ournal et al., 2017). "One-third of mothers who participated in the study reported a history of MHDs (maternal mental health disorder). This vulnerable group perceives themselves as less ready for discharge home with their infant, indicating an unmet need for provision of enhanced transition services" (Ournal et al., 2017 pg. 71).

The impact of a transitional home program affects re-hospitalization rates with medically compromised infants. Rates of re-hospitalization decreased between year one and three by $42 \%$ due to family-centered care for mother and infant, psychological support, parent education and medical support (Ournal et al., 2016). Parents who experienced a NICU stay and have transitioned home, describe ways in which the system could be improved to prepare parents better. For example, parents could be provided with information on knowledge sources, parent roles, communication, financial resources, and emotional support (Ournal et al., 2016). There are programs developed by researchers to help clinicians use daily practices to help parents feel confident when taking a NICU baby home for the first time.

Mothers who have a child in the NICU have a 24/7 support system such as, medical doctors, nurses, rehabilitation team and lactation consultants to assist the family with questions and concerns. When the family is discharged home, professional support decreases dramatically, and there are reported difficulties of caring for their baby. The family experiences psychological stress due to the preterm infant being admitted to the NICU (Adama et al., 2016). In response to their infant being discharged from the NICU, parents experienced: distress, distance parenting, stress from not being informed during the transition process, and a lack of communication across healthcare settings (Ballantyne et al., 2017). Parents of preterm infants ( $<37$ weeks) transitioning home felt that parenting alters the parenting role, is physically demanding, socially disruptive, 
MATERNAL MENTAL HEALTH WITHIN TRANSITION

and ultimately, the preterm infant requires enhanced support from health care professionals (Boykova, 2016).

In a study by Tully Stuebe, \& Verbiest, (2017) 87 individuals convened in North Carolina, which included: mothers, nurses, physicians, health department staff, breastfeeding coordinators, clinic directors, and Women Infant and Children leaders and representatives from numerous associations. Themes were identified from mothers partaking in discussing their postpartum stories: mood and emotional wellbeing, medications, substances and exposures, infant care and feeding, physical recovery from childbirth, sleep, and fatigue, sexuality, contraception, and birth spacing (Tully, Stuebe, \& Verbiest, 2017). Mothers stated that it is "overwhelmingly difficult" to process extensive information as they are being discharged from the hospital to return home with a high- risk newborn. The article describes the fourth trimester being a mother and infant mutually dependent unit, both behaviorally and physiologically. The intensive caregiving that is necessitated by infants requires substantial investment and adjustment. Some of the women experiencing these demands were compounded by their own personal and emotional health challenges as they are adapting to their "new normal" (Tully, Stuebe, \& Verbiest, 2017). Even though many women experience an uncomplicated early postpartum period, some encounter challenges that lead to confusion and distress (Tully, Stuebe, \& Verbiest, 2017).

In a meta-synthesis conducted by Adama et al., (2016) categories were obtained from 12 qualitative studies which grouped common themes. Parents had mixed feelings about being discharged, some reported feeling happy, and others felt scared or a mixture of both. Parents lived in constant fear: since parents were not adequately prepared, the fear stemmed from the lack of knowledge regarding caring for the infant. In some parents, fear took over their everyday 
MATERNAL MENTAL HEALTH WITHIN TRANSITION

lives. Mothers reported that social support enabled them to spend time with their infant to understand cues; thus, leading them to identify and care for their infants' needs (Adama et al., 2016).

\section{Chapter III: Project Description}

\section{Participants}

The capstone project will be completed in collaboration with Stars Therapy Services in the Summer and Fall of 2019. Stars Therapy Services provides early intervention services throughout Southern California, with offices located in Chula Vista and Riverside, CA. Participants are mothers who have a child enrolled in the California Early Start Program for San Diego County and the San Andreas Regional Center. Stars Therapy Services is a multidisciplinary team of early interventionists serving children ages 0-3 across Southern and Northern California. The team providing services include early interventionists, behavioral therapists, pediatric occupational therapists, physical therapists, registered behavior technicians, certified occupational therapy assistants, board certified behavior analysts, and speech therapists. Services are provided in the child's natural environment.

This capstone project intends to design a program through semi-structured interviews and parent questionnaires to gather information regarding difficulty transitioning home with a highrisk infant. After reviewing the information given during the assessment phase, themes will be identified to determine potential changes in roles, routines, and environments, resulting in an occupational imbalance upon return home from the NICU.

Families will be selected to participate in the needs assessment who meet the inclusion criteria through an Individual Family Service Plan (IFSP), which includes having a baby who graduated in under 37 weeks from the NICU. The inclusion criteria were considered based on 
MATERNAL MENTAL HEALTH WITHIN TRANSITION

premature babies are considered those born at less than 37 weeks gestation (Adama et al., 2016). The sample will be volunteer mothers of children receiving EI services with Stars Therapy Services. The student will recruit participants through conversations with the mothers during the initial stages of observation alongside the licensed occupational therapist on staff. The student will ask families to sign a written consent form stating information obtained will be fully protected under the Health Insurance Portability and Accountability Act and the data collection process during intervention sessions will be used for educational purposes affiliated with postgraduate work. Interviews will be conducted in the home within the last fifteen minutes, postintervention with the child, in order to ensure service delivery will not be affected.

\section{Materials and Design}

The interview form developed for the purpose of this capstone project is: Exploring Mothers Roles, Routine and Environment after Discharge (see Appendix A). Questions are influenced by a MOHO assessment tool, the Occupational Performance History Interview (Kielhofner, 1998). Interview questions focus on the mother's routines, roles, and environment pre and post hospitalization. The Survey of Well-being of Young Children was adapted to address the influence of the mother's home environment pre and post hospitalization (Tufts Medical Center, 2019).

The questionnaire used for the purpose of this capstone project is the Edinburgh Postnatal Depression Scale (see Appendix B) (Lydsdottir et al., 2019). The EPDS is a validated tool to help identify mothers at risk for perinatal depression. The EPDS is a tool used throughout the world in various practice settings by health professionals (Lydsdottir et al., 2019). The EPDS consists of 10 questions that can be completed in less than 5 minutes. Responses are scored $0,1,2,3$ according to the severity of the symptom. The total score of 30 points is determined by 
MATERNAL MENTAL HEALTH WITHIN TRANSITION

adding together the scores from 10 questions. Validation studies determined women scoring 9 or more points may need a referral for appropriate licensed health personnel's (Lydsdottir et al., 2019). Both the interview and questionnaire will be used throughout the data collection process to capture potential outcomes for future program development.

A needs assessment will be completed using a descriptive qualitative design and a phenomenological approach was chosen for the description and exploration of transitional challenges. Methods published throughout peer-reviewed literature uses the qualitative descriptive approach. A phenomenological approach seeks understanding through participants' lived experiences. The information gathering is conducted primarily through conversations, interviews, and observations. Open-ended questions will be asked in the interview to allow participants to describe their experiences in depth through a personal viewpoint without a preconceived notion of their experiences.

Data collection includes observations from a structured checklist and interviews to gather a full description of participants' experiences transitioning home with high-risk infants. It will also include a formal questionnaire. The student will ask the mothers to fill out the EPDS as if they recently came home from the NICU, due to the possibility of the family being discharged home from the NICU months prior to the student's capstone dissemination. Results from the interview, questionnaire and observations will allow the student to identify themes or generalize how a certain phenomenon changed the mothers' roles, routines, and the environment from those who have lived the experience.

Themes will be identified from the results of the interview and questionnaire to develop a needs assessment to influence program curation. Qualitative data will be organized, and parental 
MATERNAL MENTAL HEALTH WITHIN TRANSITION

narratives will be used to create content under three categories: roles, routines, and environment. Program development will then follow based on the need's assessment.

\section{Procedures and Timeline}

The first 2-4 weeks of this capstone experience will be focused on building rapport with families through observations alongside the treating occupational therapist. Completing a needs assessment to assess the occupational needs of mothers during the transition from the NICU to home is expected to take 2-3 weeks. The needs assessment will include observation, and interviews with families and therapists. The following 3-4 weeks will be formulating and delivering a questionnaire for mothers to determine how their occupations are impacted, and conducting interviews to compare the impact on roles, routines, and environment post-transition home from the NICU. The next 4-5 weeks will be developing and proposing a program that addresses occupational performance challenges of early motherhood, including the complexities of establishing results to promote positive maternal mental health. The final 2 weeks will be proposing the program to the therapists and Stars Therapy Services. Dissemination of the project will be given as a poster presentation for the general population to view.

\section{Actual Procedures and Timeline}

The first 4 weeks of this capstone experience focused on building familiarity with families through observations with the treating infant educator. Data collection was taken alongside early intervention provider on staff during the capstone experience. A needs assessment was completed to assess the occupational needs of mothers during the transition from the NICU. The interview portion on average took 45 minutes to an hour to complete in its entirety. The nature of early intervention included canceled sessions and other caregivers attending sessions in place of the mother. Since the student had a 15-minute window to complete 
MATERNAL MENTAL HEALTH WITHIN TRANSITION

a portion of the interview with participants on the schedule to be seen once a week, data collection took longer than expected.

The needs assessment included observations from a structured checklist, delivering a questionnaire for mothers to determine how their occupations are impacted, and to conduct interviews to compare the impact on roles, routines, and environment post-transition home from the NICU. After the data was collected, the student then proceeded with developing and proposing a program addressing occupational performance challenges of early motherhood, including the complexities of establishing results to promote positive maternal mental health. During the final 2 weeks, a developed program was delivered to the participating families, Stars Therapy Services, and to the OT profession at large. Dissemination of the capstone project will be given as a poster presentation for the general population to view at The University of St. Augustine for Health Sciences research day.

\section{Chapter IV: Results and Analysis}

\section{Data Analysis}

Data analysis for this capstone project consisted of identifying common themes and concepts derived from mothers' lived responses to the EPDS needs assessment and to the interview questions. After a thorough initial reading of completed interviews, the student identified themes throughout the perinatal period. The student reviewed and scored the EPDS assessment to identify common responses from mothers who scored higher than 9 points. Common identified themes were (1) felt unhappy that the mother has been crying, (2) anxious or worried for no good reason, (3) self -blame when things went wrong, and (4) less enjoyment. Cross-referencing the EPDS results and open-ended interview content allowed the student to 
MATERNAL MENTAL HEALTH WITHIN TRANSITION

compare, contrast, and identify emerging meanings for program curation to close the gap in maternal mental health through education, collaboration, and advocacy.

\section{Results}

There were 12 parents who participated in the interviews (11 mothers and one father) who experienced a NICU stay and preterm birth. All participants were married except one. All participants had family support within the surrounding area. Four of 12 infants were discharged home with a devices such as a feeding tube, oxygen and/or a sleep apnea machine. Ten participants completed the EPDS with three mothers scoring 9 points and above. Relating to existing the statistical data of 1 in 5 mothers experiencing a perinatal mood disorder (Vismara, 2017), $30 \%$ of mothers who participated in the capstone project scored high for possible depression within a week of being discharged home from the NICU.

Participants described a spectrum of how their routine, role, and environment changed throughout the perinatal period (before and after giving birth). Themes and specific needs relative to each category surfaced throughout the interview of each parent's journey. Themes were sub-categorized under routine, role, and environment.

\section{Routine.}

Feeding. Feeding routines were challenging on average within the first nine months upon NICU discharge. All mothers reported their number one stressor within their routine was breastfeeding. Many mothers had support with breastfeeding when they were in the hospital from lactation consultants. However, when they were discharged home, problems emerged. These included maintaining enough milk supply, baby not latching, and being constantly worried about the baby receiving enough milk to meet proper developmental needs. All the mothers that were interviewed terminated breastfeeding after a few weeks and switched to a formula bottle. One 
MATERNAL MENTAL HEALTH WITHIN TRANSITION

mother reported waking up every 2 hours throughout the day and night to feed her baby because she was worried her baby was not receiving enough milk. She was not given resources or transferable education to support a feeding routine within the home. As one mother expressed, "Trying to stay on a feeding routine and overcome the challenges of breastfeeding alone became the number one stressor throughout my day. Eventually, I had to give up because I couldn't do it anymore. Breastfeeding took over my life, not in a good way." During discharge from the NICU, mothers were not given discharge information for breastfeeding and many felt they could not transfer their skills from the hospital to the home environment.

Sleep routine. Participants identified the need for an established sleep routine because their intermittent sleep schedule was causing the mothers emotional stress. As one participant stated, "I wish I would have had help and the resources to establish a sleep routine. There were some days I was running on two hours of sleep, and it started to affect my mood and how I treated people. I was so worried about my baby getting enough sleep that I did not focus on myself because it wasn't about my needs anymore." Parents needed to feel prepared for the level of fatigue that could surface after discharge to adequately establish a routine at home. Some mothers reported eventually establishing a sleep routine after six months of being discharged home. The participants who had family support in the home were able to relieve the mother from caregiving duties to allow her to take care of herself.

Self-care. Once home, the mother's self-care routine was overlooked because it was not considered a priority. When the student asked a mother about her self-care routine, she answered with the following response: "What is self-care when you're a new mother to a baby who needs 24/7 support? Before I had my baby, I would love to paint my nails, spend 30 minutes in the shower washing my hair, and the occasional one a week face mask. Now my showers consist of 
MATERNAL MENTAL HEALTH WITHIN TRANSITION

10 minutes at most. I don't remember the last time I did my self-care routine.” Another participant stated, "One time when my mother in law was over helping me with the baby, I was able to wash my hair for 20 minutes, that was everything." All mothers reported not participating in a self-care routine because they were preoccupied by the health of their preterm infant.

Social participation/leisure. After discharge, all the mothers and the father interviewed did not participate in any leisure or social activities with friends. Parents with complex needs felt guilty for giving other people their undivided attention. During the interviews, mothers described that prior to giving birth, social participation and leisure activities were essential to them. Some weekly date nights consisted interacting with their social circle of friends. As one mother stated, "Before I had my baby, we had the house were everyone would hang out at. When I brought my baby home, I did not see my friends anymore. I was nervous for people to come over because my baby was so little. It was hard to relate to my friends because they do not have children. I became lonely at times and wanted to find a mom group but was not sure how. Now I am finding friends with children, and it has helped me get out of the house more" (personal communication, October, 2019).

Date nights with their spouse turned into staying within their home environment watching Netflix because they were nervous taking their baby out in public secondary to the potential of their baby getting sick.

\section{Role.}

Additional responsibilities. Mothers reported having several additional responsibilities caring for their preterm infant. Mothers had an average of four doctor appointments per week, depending on the infant's medical needs at that time. When transitioning home from the NICU, parents needed to be trained in the basics of everyday care. As one mother expressed, 
"It is difficult to manage the first nine months. It was exhausting adjusting to my baby being home. I had to be trained on the APNEA monitor, make sure my baby had PT and OT appointments once a week each. Numerous doctor appointments for respiratory, eye exam, pediatrician, and my OBGYN. I needed to make sure my baby was working towards reaching typical developmental milestones. It became very overwhelming for me as I was trying to juggle other things in my life, and I wish I could have managed my time more" (personal communication, October, 2019).

Mothers described having adequate knowledge in terms of their infant's needs regarding potential equipment in the NICU. Upon transitioning home, home equipment was very different from hospital-grade equipment, and participants needed multiple training sessions to feel comfortable using it.

Relationships. Relationships with friends, family, and spouse changed during the transition home from the NICU. Mothers described their relationship with their spouse growing into a mature relationship as their role with their friends became almost non-existent. One mother who was not married and did not have spousal support scored the highest on the EPDS (26/30) and described her role as a mom as, "stressful" and "overwhelming." Some days she did not want to get out of bed secondary to anxiety and depression episodes. She was not able to maintain relationships with her friends due to her sole role as a mom taking priority. Upon learning the assessment results, the student revisited other participating mothers and asked, “How would you be able to cope being a new mom without spousal support?" All mothers reported that they would not be able to cope without the help of their husbands. As one mother stated, "My mental health would have been more severe if I did not have my husband to support me." Some mothers had weekly traditions participating in family dinners and were unable to join 
MATERNAL MENTAL HEALTH WITHIN TRANSITION

for months because they were nervous their baby would get readmitted into the NICU by being exposed to other environments.

Preconceived notions. Fifty percent of interviewed mothers had a preconceived idea that their routine would reflect certain expectations upon discharge. Mothers with older children tried to demonstrate the same routine, which made it more difficult. As one mom described: "Every day was different, I thought it was going to be X, Y \& Z, it turned out to be the exact opposite of any expectations that I had. It was a lot harder than I anticipated.” Another mother described her experience as "My baby changed each day; it was hard for me to understand his stress cues and I had to adapt. I thought I would have had more time to get the house ready before his arrival, but that wasn't the case."

\section{Environment.}

NICU environment and staff relationships. Standard terms describing the NICU environment were "stressful" and "scary." Mothers were triggered by machines sounding off from neighbor neonates because they did not understand the meaning behind the numbers displayed on the monitor. It took mothers a few visits to build familiarity with the environment and education from medical staff to feel comfortable. All mothers reported building a relationship with their lead nurse. When mothers were able to construct a staff-parent relationship, it put them at ease. The lead nurse communicated with the mothers on updates regarding their infant's status and assessment results when the mother was not on site. A mother described her staff-parent relationship: "We got assigned specific nurses to build relationships with. We added one of our NICU nurses on Facebook. She was so supportive and amazing. She really advocated for the best for her patients and families." Having medical staff who were thoughtful, supportive and provided a calming approach to care was a relief. 
MATERNAL MENTAL HEALTH WITHIN TRANSITION

Home environment. When transitioning home, mothers reported being triggered and always nervous that their baby would be readmitted into the NICU. Home upkeep was important to mothers due to a clean environment aiding in building their new infants' immune system. Ninety percent of mothers reported having family in the surrounding area and living in the home to help with house upkeep. The remaining $10 \%$ who did not have family support reported being chronically fatigued and stressed. During the prenatal period, their environment was described as "quiet" and mothers were able to be spontaneous and social within the surrounding environment. During the postnatal period, mothers had to be more conscious of their home organization. As one mother stated, "My home environment was organized chaos. It was busy, messy and hectic due to dirty dishes and laundry everywhere. We just had to learn sometimes to embrace the mess and make a priority list." All interviewed mothers replicated the NICU environment for the first few weeks living at home regarding lights, noise, and temperature.

Changes upon reflection. The student asked the participants to reflect on their past home environment bringing their infant home, and if they would have changed anything. There were a few common responses, such as having projects completed upon their infant's arrival, eliminating noise stressors such as dogs, neighbors, and other persons in the home, taking parenting classes to help plan for the unexpected, and wishing for more social participation. Ninety-five percent of the mothers' home environments were not set up before delivery due to premature birth. When transitioning home, lack of an organized home environment was an additional stressor that contributed to the mother feeling overwhelmed. It took some participants months to set up their home while in conjunction, taking care of a medically fragile infant with additional medical needs. 
MATERNAL MENTAL HEALTH WITHIN TRANSITION

\section{Chapter V: Discussion and Conclusion}

\section{Discussion}

The participants within this capstone project described a spectrum of needs experienced after discharge from the NICU. Through a structured needs assessment, the nature of maternal needs evolved throughout the perinatal period. Themes that emerged from the semi-structured interviews were noteworthy and have implications for future OT practice. These needs consistently centered around: routine, role, and environment and how they could promote positive maternal mental health. These findings were consistent with a review of the literature on parents' perspectives on transitions home from the hospital. The finding that $30 \%$ of women reported symptoms of possible depression suggests that screening for PPD in mothers of infants at high risk is essential (Pizur-Barnekow, \& Erickson, 2011). During the transition to motherhood, women experience shifts in psychological and physiological processes that have consequences for social interactions, mood states, and roles (Pizur-Barnekow, 2010).

Pierrehumber et al. (2003) found significant associations between perinatal mood disorders and infant sleeping and feeding outcomes, such as more problematic occupational patterns. These findings suggest that early interventionists need to be aware of maternal mental health, especially when infants have complex medical concerns.

Early intervention providers could use the framework of the MOHO to support family routines. Though supportive research on OT's role available in the literature, participants in the project reported that they struggled to reclaim their routines upon returning home from the hospital. Mothers recounted not having an established routine upon discharge that included, a feeding and sleep routine. Mothers who had older children tried to demonstrate the same routine as they did with their other children, which made the experience even more challenging. Mothers 
MATERNAL MENTAL HEALTH WITHIN TRANSITION

maintained a NICU routine during the first few months at home and then had to transition to their own within the home. Self-care was overlooked, and social participation and leisure activities dwindled.

Although the mothers wished they would have had a structured routine to relieve daily stressors, several mothers raised the counter perspective of praising a heavy co-occupational routine. This suggests that by adopting a co-occupational routine, occupational therapists can play an important role in infants' feeding, sleeping, caring, comforting, home management, and occupational activities (Slootjes et al., 2016).

Second, the role of having additional responsibilities with an infant who has medical needs placed mothers in a position of feeling overwhelmed. In the context of motherhood, a preconceived role is a work, familial, and social role performance, house management, relationships, and breastfeeding (Slootjes et al., 2016). An important finding worth noting is mothers were not able to transfer occupational roles throughout the perinatal period. Many moms had a preexisting role of being a friend, participating in social events, and having a career. Transitioning into the postnatal period, mothers reported less participation in their role as a friend, sacrificing their career, social events and not being able to maintain house management.

The potential for OT assessments, advocacy and recommendations during the perinatal period could achieve lowered incidences of maternal stress (Slootjes et al., 2016). If a woman does not engage in roles typical of motherhood and believes that she has the competence that others expect, this may result in altered role perceptions (Pizur-Barnekow \& Erickson 2011). Furthermore, if the attitudes and actions of early interventionists or health care professionals do not reflect a belief in her competence, and if the mother does not personally experience engaging 
MATERNAL MENTAL HEALTH WITHIN TRANSITION

in the occupation of typical "mothering" behaviors, she may inadequately fulfill that role (Pizur-Barnekow \& Erickson 2011).

This capstone project confirms that the environment plays a critical role in maternal wellness. Within the NICU environment, monitors sounding off, the infant's size, and lines and leads placed multifactorial stressors on the mother. The recognition of family needs surrounding educational empowerment from medical staff improved parental outcomes, decreased stress and anxiety, and improved parental confidence. The use of educational empathy from staff improved the understanding of discharge care with confidence. A review of mother's responses regarding their home environment post discharge showed unpreparedness with organization, eliminating additional noise stressors, responding to infant's stress cues, and managing home upkeep. Participants constantly described their home environment as stressful, loving, overwhelming, chaotic, and busy. A systematic review of family centered hospital to home transition processes showed education and performing a transition needs assessment was associated with improved patient outcomes and decrease in health care use (Desai, Popalisky, Simon \& Mangione-Smith, 2015).

\section{Limitations}

This capstone has several limitations. This project, similar to any phenomenological study, represents the perspective of a small sample size, and findings should be validated using quantitative methods for a more extensive representation of the population. Participants had predominately spousal and family support within the home or in the surrounding area, so mothers without support needs to be further explored. This capstone project did not have specific inclusion and exclusion criteria, except the participants having a NICU experience. Not all interviews were delivered in English, as two participants solely spoke Spanish and conversations 
MATERNAL MENTAL HEALTH WITHIN TRANSITION

were communicated through a translator. Lastly, thematic analysis was not conducted using a coding approach as it might limit the validity of the data.

\section{Implications for Occupational Therapy}

The current capstone project examined maternal mental health within the transition from the NICU, home. The main objective of this paper was to provide education, collaboration and advocacy that supports the inclusion of maternal mental health within the scope of occupational therapy. Including screening of maternal routine, role, and environment in early intervention is consistent with serving the mother within the philosophy of family-centered care. Research has indicated that maternal wellness is related to the maternal-infant relationship which consequently influences interactions and neurological development of the infant (Johnson \& Marlow, 2014). Maternal-infant interactions occur during daily co-occupational engagement and experience with the $\mathrm{MOHO}$ as a theoretical framework of reference, attention to roles, routine and environment on maternal wellness and experience working within a holistic form of practice makes occupational therapists uniquely qualified to address the needs of mothers who are experiencing any perinatal mood disorder.

OT has roots in mental health including practical instruction and psychosocial intervention. A potential for group support for mothers recently discharged through an early intervention program or the local community may promote social participation and reduce the stigma that is found surrounding mental health. Engaging mothers in support groups may be beneficial in alleviating symptoms and leisure identification. Provision of care coordination services through identification of local resources that are available may link mothers to appropriate programs. Furthermore, it may be less intimidating attending a group with mothers 
MATERNAL MENTAL HEALTH WITHIN TRANSITION

whose baby had a NICU experience that focuses on the co-occupations of motherhood in conjunction with building social support.

Given the current documented statistics of women experiencing a perinatal mood disorder, it gives OT the opportunity to pave the path in aligning a mother's routine, role and environment to better suit her needs. Many mothers were not able to set up their home environment to their liking due to their baby being born prematurely leading to mothers feeling anxious, overwhelmed, stressed and exhausted. Due to experience with task analysis, occupational therapists can play a role in house management, coping strategies, social participation, leisure exploration, education, resource referral, and energy conservation etc. Occupational therapists working in the field of pediatrics can support the impacts of performance for mothers throughout the transitional perinatal period.

\section{Conclusion}

In conclusion, this paper further refines the definition of how OT can support mothers throughout the transition process by representing the mother's perspective on transitions home from the NICU and demonstrating how their role, routine and environment evolve from the point of discharge. This finding has important implications for occupational therapy practice regarding interventions that are intended to promote positive maternal mental health. As such, hoping to validate mothers' perceptions that will empower professionals and other mothers to feel confident and prepared for their new baby after discharge home from the NICU. In closing, occupational therapists are equipped with the skills to address maternal mental health concerns and its impacts on maternal wellness by improving the well-being and quality of life for all mothers. 
MATERNAL MENTAL HEALTH WITHIN TRANSITION

\section{References}

Adama, E. A., Candidate, R. N., Bayes, S., Rm, R. N., Lecturer, S., \& Sundin, D. (2016). Parents experiences of caring for preterm infants after discharge from Neonatal Intensive Care Unit: A meta-synthesis of the literature. Journal of Neonatal Nursing, 22(1), 27-51. https://doi.org/10.1016/j.jnn.2015.07.006

American Occupational Therapy Association. (2017). Mental health promotion, prevention, and intervention in occupational therapy practice. American Journal of Occupational Therapy, 71(Suppl. 2), 7112410035. https://doi. org/10.5014/ajot.2017.716S03

Ballantyne, M., Orava, T., Bernardo, S., McPherson, A. C., Church, P., \& Fehlings, D. (2017). Parents' early healthcare transition experiences with preterm and acutely ill infants: A scoping review. Child: Care, Health and Development, 43(6), 783-796. https://doi.org/10.1111/cch.12458

Boykova, M. (2016). Newborn and infant nursing reviews life after discharge: What parents of preterm infants say about their transition to home. Newborn and Infant Nursing Reviews, 16(2), 58-65. https://doi.org/10.1053/j.nainr.2016.03.002

Boykova, M., \& Kenner, C. (2012). International connections: Transition from hospital to home: Post-neonatal intensive care unit discharge: A global perspective. Newborn and Infant Nursing Reviews, 12(4), 184-186. https://doi.org/10.1053/j.nainr.2012.09.004

Cherry, A. S., Blucker, R. T., Thornberry, T. S., Hetherington, C., McCaffree, M. A., Gillaspy, S. R., \& Cherry, A. S. (2016). Postpartum depression screening in the Neonatal Intensive Care Unit: Program development, implementation, and lessons learned. Journal of Multidisciplinary Healthcare, 9, 59-67. https://doi.org/10.2147/JMDH.S91559 
MATERNAL MENTAL HEALTH WITHIN TRANSITION

Desai, A. D., Popalisky, J., Simon, T. D., \& Mangione-Smith, R. M. (2015). The effectiveness of family-centered transition processes from hospital settings to home: A review of the literature. Hospital Pediatrics, 5(4), 219-231. https://doi.org/10.1542/hpeds.2014-0097

Dusing, S. C., Van Drew, C. M., \& Brown, S. E. (2012). Instituting parent education practices in the neonatal intensive care unit: An administrative case report of practice evaluation and statewide action. Physical Therapy, 92(7), 967-975. https://doi.org/10.2522/ptj.20110360

Evans, T., Whittingham, K., Sanders, M., Colditz, P., \& Boyd, R. N. (2014). Infant behavior and development: Are parenting interventions effective in improving the relationship between mothers and their preterm infants? Infant Behavior and Development, 37(2), 131-154. https://doi.org/10.1016/j.infbeh.2013.12.009

Goodman, J. H., \& Santangelo, G. (2011). Group treatment for postpartum depression: A systematic review. Archives of Women's Mental Health. https://doi.org/10.1007/s00737011-0225-3

Hara, M. W. O., Wisner, K. L., \& Asher, H. (2019). Best practice \& research clinical obstetrics and gynaecology perinatal mental illness: Definition, description and etiology. Best Practice \& Research Clinical Obstetrics \& Gynaecology, 28(1), 3-12. https://doi.org/10.1016/j.bpobgyn.2013.09.002

Heidari, H., Hasanpour, M., \& Fooladi, M. (2017). Stress management among parents of neonates hospitalized in NICU: A qualitative study. Journal of Caring Sciences, 6(1), 29-38. https://doi.org/10.15171/jcs.2017.004 
MATERNAL MENTAL HEALTH WITHIN TRANSITION

Howe, T.-H., \& Wang, T.-N. (2013). Systematic review of interventions used in or relevant to occupational therapy for children with feeding difficulties ages birth-5 years. American Journal of Occupational Therapy, 67, 405412.

http://dx.doi.org/10.5014/ajot.2013.004564

Johnson, S., \& Marlow, N. (2014). Seminars in fetal \& neonatal medicine growing up after extremely preterm birth: Lifespan mental health outcomes. Seminars in Fetal and Neonatal Medicine, 19(2), 97-104. https://doi.org/10.1016/j.siny.2013.11.004

Karin, J., Britt-Marie, T., \& Jens, S. (2003). From alienation to familiarity: Experiences of mothers and fathers of preterm infants. Journal of Advanced Nursing, 43(2), 120-129. Retrieved from http://search.ebscohost.com/login.aspx?direct=true\&db=edsovi\&AN=edsovi.00004471.2 $\underline{00307020.00003 \& \text { site }=\text { eds-live }}$

Kielhofner, G. (1998). A user's manual for the occupational performance history interview (OPHI-II). Bethesda, MD Model of Human Occupation Clearinghouse 1998.

Kurtz, S., Levine, J., \& Safyer, M. (2017). Ask the question: Screening for postpartum mood and anxiety disorders in pediatric primary care. Current Problems in Pediatric and Adolescent Health Care. https://doi.org/10.1016/j.cppeds.2017.08.002

Lazarus, K., \& Rossouw, P. (2015). Mothers' expectations of parenthood. The impact of prenatal expectations on self- esteem, depression, anxiety and stress post mothers' expectations of parenthood: The impact of prenatal expectations on self-esteem, depression, and anxiety. International Journal of Neurology, 3(August), 102-123.

https://doi.org/10.12744/ijnpt.2015.0102-0123 
MATERNAL MENTAL HEALTH WITHIN TRANSITION

Lydsdottir, L. B., Howard, L. M., Olafsdottir, H., Thome, M., Tyrfingsson, P., \& Sigurdsson, J. F. (2019). The psychometric properties of the Icelandic version of the Edinburgh Postnatal Depression Scale (EPDS) when used prenatal. Midwifery, 69, 45-51. https://doi.org/10.1016/j.midw.2018.10.009

Maas, A. J. B. M., Vreeswijk, C. M. J. M., Braeken, J., Vingerhoets, A. J. J. M., \& van Bakel, H. J. A. (2014). Determinants of maternal fetal attachment in women from a communitybased sample. Journal of Reproductive \& Infant Psychology, 32(1), 5-24. https://doi.org/10.1080/02646838.2013.853170

O’Hara, M. W., \& Wisner, K. L. (2014). Perinatal mental illness: Definition, description and aetiology. Best Practice and Research: Clinical Obstetrics and Gynaecology. https://doi.org/10.1016/j.bpobgyn.2013.09.002

Ournal, T. H. E. J., Ediatrics, O. F. P., Berman, L., Raval, M. V, Ottosen, M., Mackow, A. K., ... Goldin, A. B. (2019). Parent perspectives on readiness for discharge home after neonatal. The Journal of Pediatrics, 205, 98-104.e4. https://doi.org/10.1016/j.jpeds.2018.08.086

Ournal, T. H. E. J., Ediatrics, O. F. P., Mcgowan, E. C., Du, N., Hawes, K., Tucker, R., ... Vohr, B. (2017). Maternal mental health and neonatal intensive care unit discharge readiness in Mothers of Preterm Infants. The Journal of Pediatrics, 184, 68-74. https://doi.org/10.1016/j.jpeds.2017.01.052

Ournal, T. H. E. J., Ediatrics, O. F. P., Vohr, B., Mcgowan, E., Keszler, L., Alksninis, B., ... Tucker, R. (2016). Impact of a transition home program on rehospitalization rates of preterm infants. The Journal of Pediatrics, 181, 86-92. https://doi.org/10.1016/j.jpeds.2016.10.025 


\section{MATERNAL MENTAL HEALTH WITHIN TRANSITION}

Pierrehumbert, B., Nicole, A., Muller-Nix, C., Forcada-Guex, M., \& Ansermet, F. (2003). Parental post-traumatic reactions after premature birth: Implications for sleeping and eating problems in the infant. Archives of Disease in Childhood: Fetal and Neonatal Edition, 88(5), 400-404.

Pizur-Barnekow, K. (2010). Maternal health after the birth of a medically complex infant: Setting the context for evaluation of co-occupational performance. American Journal of Occupational Therapy, 64, 642-649. https://doi: 10.5014/ajot.2010.08160

Pizur-Barnekow, K., \& Erickson, S. (2011). Perinatal posttraumatic stress disorder: Implications for occupational therapy in early intervention practice. Occupational Therapy in Mental Health, 27(2), 126-139. https://doi.org/10.1080/0164212X.2011.566165

Pizur-Barnekow, K., Kamp, K., Cashin, S., Pizur-, K., \& Kamp, K. (2014). An investigation of maternal play styles during the co-occupation of maternal-infant play. Journal of Occupational Science, 21(2), 202-209. https://doi.org/10.1080/14427591.2012.724379

Podvey, M. (2018). Maternal health and occupational therapy: A good fit. SIS Quarterly Practice Connections, 3(2), 17-19

Slootjes, H., McKinstry, C., \& Kenny, A. (2016). Maternal role transition: Why new mothers need occupational therapists. Australian Occupational Therapy Journal, (2), 130. https://doi.org/10.1111/1440-1630.12225

Spittle, A., \& Treyvaud, K. (2016). The role of early developmental intervention to influence neurobehavioral outcomes of children born preterm. Seminars in Perinatology, 40(8), 542548. https://doi.org/10.1053/j.semperi.2016.09.006 
MATERNAL MENTAL HEALTH WITHIN TRANSITION

Tufts Medical Center. (n.d). The Survey of Well-being of Young Children | Floating Hospital. Retrieved from https://www.floatinghospital.org/The-Survey-of-Wellbeing-of-YoungChildren/Overview.aspx

Treyvaud, K., Inder, T. E., Lee, K. J., Northam, E. A., Doyle, L. W., \& Anderson, P. J. (2012). Can the home environment promote resilience for children born very preterm in the context of social and medical risk? Journal of Experimental Child Psychology, 112(3), 326-337. https://doi.org/10.1016/j.jecp.2012.02.009

Treyvaud, K., Ure, A., Doyle, L. W., Lee, K. J., Rogers, C. E., Kidokoro, H., Anderson, P. J. (2013). Psychiatric outcomes at age seven for very preterm children: Rates and predictors. Journal of Experimental Child Psychology 7, 772-779. https://doi.org/10.1111/jcpp.12040

Tully, K. P., Stuebe, A. M., \& Verbiest, S. B. (2017). The fourth trimester: A critical transition period with unmet maternal health needs. American Journal of Obstetrics and Gynecology, 217(1), 37-41. https://doi.org/10.1016/j.ajog.2017.03.032

Verbiest, S., Bonzon, E., \& Handler, A. (2016). Postpartum health and wellness: A call for quality woman-centered care. Maternal and Child Health Journal, 20, 1-8. https://doi.org/10.1007/s10995-016-2188-5

Vismara, L., Tully, K. P., Stuebe, A. M., \& Verbiest, S. B. (2017). Perspectives on perinatal stressful and traumatic experiences. European Journal of Trauma \& Dissociation, 1(2), 111-120. https://doi.org/10.1016/j.ejtd.2017.03.006 
MATERNAL MENTAL HEALTH WITHIN TRANSITION

\section{Appendix A}

Exploring Mothers Roles, Routine and Environment after Discharge Interview 
MATERNAL MENTAL HEALTH WITHIN TRANSITION

Exploring Mothers Roles, Routine and Environment after Acute Discharge

\section{Daily Routine}

\begin{tabular}{|l|}
\hline Describe your typical day. \\
\hline What are the most important activities in your routine? \\
\hline \\
\hline Was your daily routine significantly different before delivery? If so, how? \\
\hline \\
\hline What do you like and dislike about your current routine? \\
\hline \\
\hline What would you like to change about your routine? \\
\hline \\
\hline Does your routine allow you to participate in meaningful tasks? \\
\hline
\end{tabular}




\section{Occupational Roles}

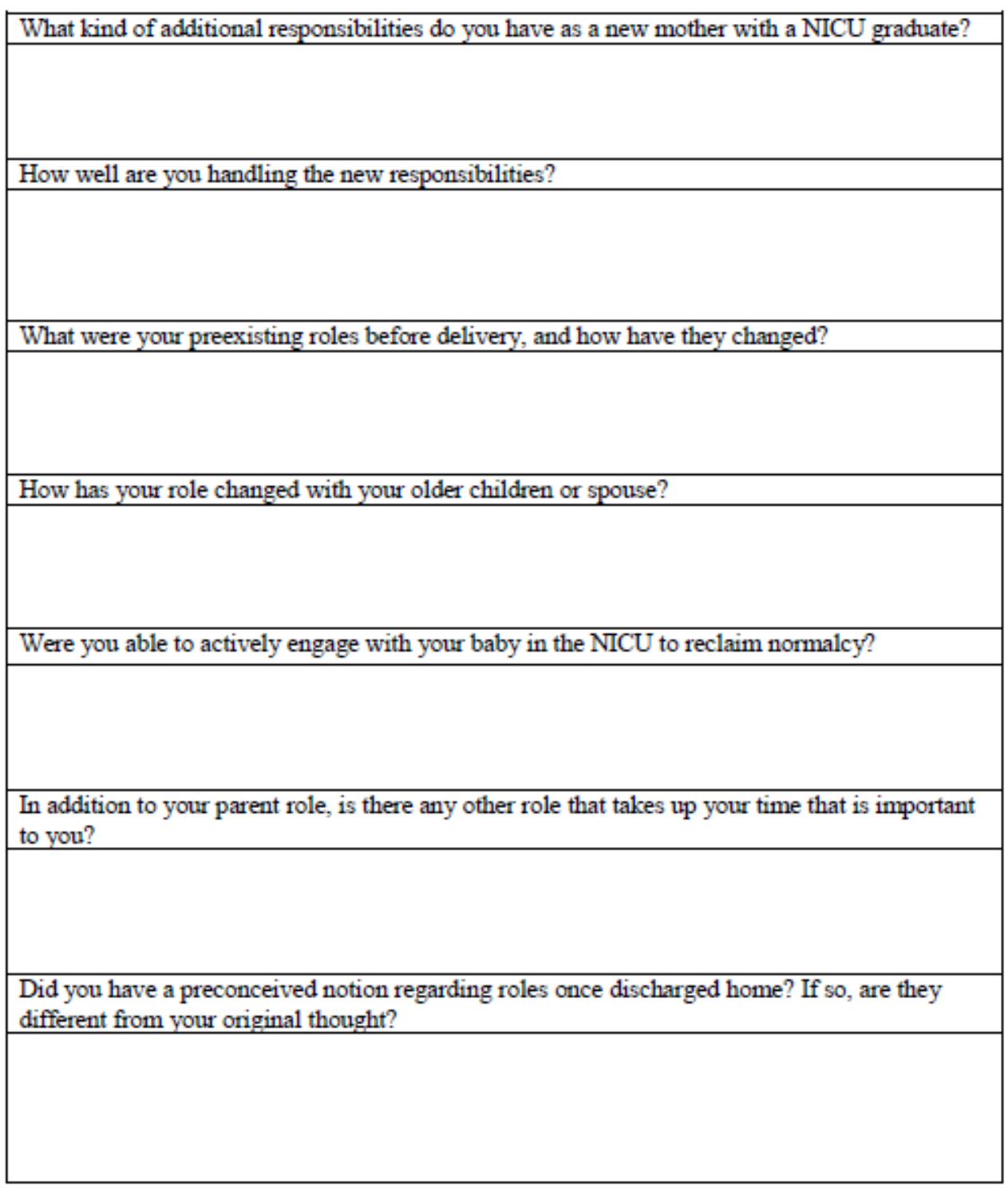


MATERNAL MENTAL HEALTH WITHIN TRANSITION

\section{Environment}

\begin{tabular}{|l|}
\hline Describe your experience with the NICU environment? \\
\hline Did you form a staff-parent relationship? Describe. \\
\hline \\
\hline What is it like in your home with your child? \\
\hline What do you have to do to upkeep your home? Do you have help? \\
\hline \\
\hline How would you describe your home environment? For example, stressful, busy, loving, \\
supporting.
\end{tabular}


MATERNAL MENTAL HEALTH WITHIN TRANSITION

Appendix B

Edinburgh Postnatal Depression Scale (EPDS) 


\section{Edinburgh Postnatal Depression Scale ${ }^{1}$ (EPDS)}

Name:

Your Date of Birth:

Baby's Date of Birth:
Address:

Phone:

As you are pregnant or have recently had a baby, we would like to know how you are feeling. Please check the answer that comes closest to how you have felt IN THE PAST 7 DAYS, not just how you feel today.

Here is an example, already completed.

I have felt happy:

L Yes, all the time

回 Yes, most of the time This would mean: "I have felt happy most of the time" during the past week.

$\square$ No, not very often Please complete the other questions in the same way.

$\square$ No, not at all

In the past 7 days:

1. I have been able to laugh and see the funny side of things - As much as I always could

- Not quite so much now

Definitely not so much now

Not at all

2. I have looked forward with enjoyment to things

ㅁ As much as I ever did

- Rather less than I used to

D. Definitely less than I used to

D Hardly at all

"3. I have blamed myself unnecessarily when things went wrong

$\square$ Yes, most of the time

ㅁ Yes, some of the time

Not very often

No, never

4. I have been anxious or worried for no good reason

$$
\begin{aligned}
& \text { No, not at all } \\
& \square \quad \text { Hardly ever } \\
& \square \quad \text { Yes, sometimes } \\
& \square \quad \text { Yes, very often }
\end{aligned}
$$

"5 I have felt scared or panicky for no very good reason

$$
\begin{aligned}
& \text { Yes, quite a lot } \\
& \square \quad \text { Yes, sometimes } \\
& \square \quad \text { No, not much } \\
& \square \quad \text { No, not at all }
\end{aligned}
$$

"6. Things have been getting on top of me

- Yes, most of the time I haven't been able to cope at all

- Yes, sometimes I haven't been coping as well as usual

№, most of the time I have coped quite well

ㅁ No, I have been coping as well as ever

"7 I have been so unhappy that I have had difficulty sleeping - Yes, most of the time

- Yes, sometimes

ㅁ Not very often

D No, not at all

"8 I have felt sad or miserable

$\square$ Yes, most of the time

ㅁ Yes, quite often

- Not very often

D No, not at all

"9 I have been so unhappy that I have been crying ㅁ. Yes, most of the time

$\square$ Yes, quite often

ㅁ. Only occasionally

ㅁo, never

*10 The thought of harming myself has occurred to me

$\square$ Yes, quite often

口 Sometimes

ㅁ Hardly ever

ㅁ. Never

Administered/Reviewed by

Date

${ }^{1}$ Source: Cox, J.L., Holden, J.M., and Sagovsky, R. 1987. Detection of postnatal depression: Development of the 10-item Edinburgh Postnatal Depression Scale. British Joumal of Psychiatry 150:782-786 .

${ }^{2}$ Source: K. L. Wisner, B. L. Parry, C. M. Piontek, Postpartum Depression N Engl J Med vol. 347, No 3, July 18, 2002. $194-199$

Users may reproduce the scale without further permission providing they respect copyright by quoting the names of the authors, the title and the source of the paper in all reproduced copies. 
MATERNAL MENTAL HEALTH WITHIN TRANSITION

Appendix C

Observation Checklist 
MATERNAL MENTAL HEALTH WITHIN TRANSITION

Observation Checklist

Date:

Child's age:

Days child spent in the NICU:

Household number.

Days out of the hospital

\begin{tabular}{|c|c|c|c|c|}
\hline Category & \multicolumn{3}{|c|}{ Response } & \multirow[t]{2}{*}{ Comments } \\
\hline Observations & Yes & No & $\mathrm{N} / \mathrm{A}$ & \\
\hline The mother's leisure & & & & \\
\hline $\begin{array}{c}\text { Does the mother look } \\
\text { anxious/hyper aroused or } \\
\text { avoiding? }\end{array}$ & & & & \\
\hline $\begin{array}{l}\text { Was/ls the mother present } \\
\text { during the first visit? }\end{array}$ & & & & \\
\hline $\begin{array}{l}\text { Is the mother confident with the } \\
\text { feeding/medication schedule? }\end{array}$ & & & & \\
\hline $\begin{array}{l}\text { Does the mother ask questions } \\
\text { during the treatment session? }\end{array}$ & & & & \\
\hline $\begin{array}{c}\text { Moms occupations } \\
\text { Talks about social participation }\end{array}$ & & & & \\
\hline $\begin{array}{c}\text { Is the dad present? } \\
\text { Do they have family local? } \\
\text { How many other kids in the } \\
\text { home? }\end{array}$ & & & & \\
\hline $\begin{array}{c}\text { What appointments do they } \\
\text { have? }\end{array}$ & & & & \\
\hline $\begin{array}{c}\text { Does the mother participate in } \\
\text { self care when the baby is } \\
\text { sleeping? }\end{array}$ & & & & \\
\hline $\begin{array}{c}\text { Mentions positive/negative } \\
\text { ability to do routines. Which } \\
\text { ones? }\end{array}$ & & & & \\
\hline
\end{tabular}

